\title{
Design and Construction of a Laboratory Bench System for the Teaching and Training of Engineers on Diagnostics of Permanent Magnet Motors
}

\author{
Francisco Blázquez, Emilio Rebollo, Carlos A. Platero, and Francisco R. Blánquez
}

\section{INTRODUCTION}

$\mathrm{H}$ ISTORICALLY, squirrel cage induction machines, powered with electronic converters, have been the most used in industrial drives topologies, both fixed speed and variable speed. The reason can be found at their robustness, reliability and low cost.

By contrast, synchronous machines, given the absence of starting torque, have only been used in high power drives where induction machines are not technologically feasible by low efficiency and low power factor. However, operating at variable speed, power converter solves the starting torque problem and they become an alternative to traditional squirrel cage machines

Nowadays, the electric drives technology tends to reduce the life cycle cost and thus provide environmental friendly solutions. Therefore permanent magnets synchronous machines have become important due to their high efficiency. The use of rare earth magnets machine designs enables a high capacity of torque at low speeds. It allows eliminating the gearbox drive which further increases efficiency.

So direct drive systems based on PMSM are a reality in many applications, such as wind power generation [1], lifts [2], electric train traction systems [3], ship propulsion [4], electric traction vehicles [5] or household appliances [6]

The use of rare earth PMSM has some technological and economic drawbacks. From the technological point of view the temperature in the motor cannot be high because the permanent magnets are very sensitive to temperature, with low values of Curie Temp. In the worst case, when working with temperature increases above the Curie temperature, the permanent magnets are fully and irreversibly demagnetized [7]. Another disadvantage of this machine technology can be its limitation in the field weakening operating mode, also to avoid the permanent magnet demagnetization [8].

From the economic point of view the price of permanent magnets is very variable, with large fluctuations [9], which does not always be a cost effective solution. Therefore in recent years are growing the studies in order to design with Ferrite and Alnico magnets, which have lower performance but with a more stable cost [10]

In this scenario it is very necessary to train experts in the design and diagnosis of PMSM. Thus, in recent years this topic has been introduced in the subjects of 'Electrical Machines Design' and Monitoring and Diagnostics of Electrical Machines', in the Electrical Engineering Master's Degree from the Polytechnic University of Madrid.

In order to provide a more complete teaching and training to students it has developed the laboratory bench that is presented in this paper.

\section{TyPiCAL FAUltS AND METHODS OF DiAgNOSIS OF PERMANENT MAGNET SYNCHRONOUS MACHINES}

As just indicated, the permanent magnet synchronous motors PMSM are widely used in industry due to their higher torque and higher power to volume ratio. Moreover they have a better dynamic performance compared to the motors with electromagnetic excitation. In order to increase 
PMSM performance, raise their lifetime, and lower their high costs, fault prediction in PMSMs is necessary.

Fig. 1 shows the many different types of faults that can appear in PMSM drive systems. These are the stator and rotor faults, the mechanical faults such as the shaft and bearing, and the faults in power electronic components of the drive system [11]

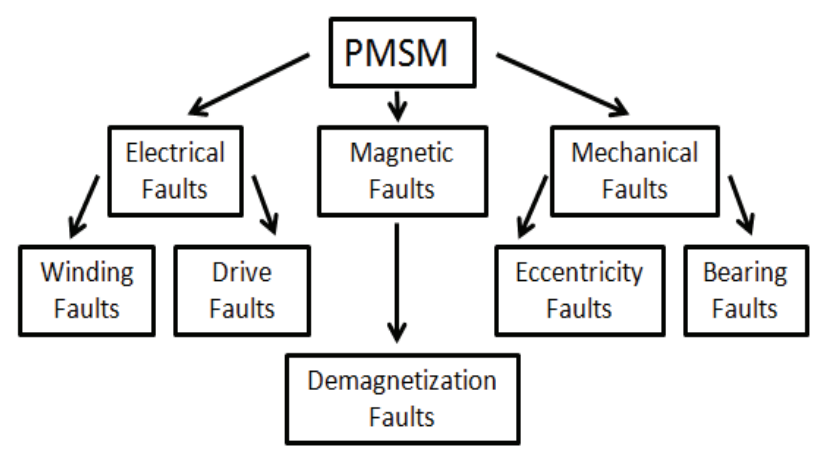

Fig. 1. Faults classification in Permanent Magnet Synchronous Motors.

The stator turn faults are caused by the breakdown of stator winding insulation system. It is deteriorated by overvoltage and thermal stresses produced by over current. The early detection of inter-turn short is quite important to prevent subsequent damage to adjacent coils and stator core. Although in the early stage of the failure the motor can continue operating, the local overheating produces a quickly propagation to adjacent turns.

In the literature appear several detection methods classified as off-line and on-line methods. Off-line methods are based on the frequency domain analysis scheme using terminal voltages [12]. On-line methods are based on the analysis and signal processing of the feeding current [13], [14].

The open fault in switching devices of inverter is perhaps the most frequent fault in power electronic converters. It arises when one or more switches are destructed by an accidental over current, or when the protection fuse is blown out. Since the inverter cannot synthesize desired voltages under this condition, it produces an increased current harmonic, large torque ripple and reduced efficiency, leading to machine stop in extreme case.

Many diagnostic methods have been proposed to detect the faulty devices in inverter switch. However practically all of them are focused on the occurrence of single faults and do not have the capability to handle and identify multiple failures [15]. Recently, some studies have presented new methods for real-time diagnostics of multiple open-circuit faults in VSI feeding ac machines [16].

Mechanical faults involve bearing and eccentricity faults. Eccentricity faults are classified in static eccentricity, dynamic eccentricity and mixed eccentricity. They occur due to manufacturing imprecision such as unbalanced mass, shaft bow, and bearing tolerance. Eccentricity may cause magnetic and dynamic problems with additional vibrations, noises, and torque pulsations.

The effects of the eccentricity faults have been reported in several studies of the magnetic field using finite-element method [17]. The diagnosis of the eccentricity fault will be very difficult if only the amplitude of the current is used. It is necessary to use the spectrum analysis of the current in order to diagnostic effects as eccentricity and misalignment [18].

The main reasons of demagnetization fault are temperature rise resulting from the operation and the armature reaction due to stator currents which opposes the remnant induction of the permanent magnets. The effect on the electromotive force of these faults has been studied using finite element analysis [19].

Other effects of the demagnetization faults are the increasing and distortion of cogging torque, but the incremental rate of the cogging torque depends on permanent magnets shape design. In [20] a diagnosis method based on the torque spectra analysis is proposed.

\section{DESCRIPTION OF THE TEACHING/TRAINING EXPERIMENTAL SETUP}

Some authors have developed experimental setups to evaluate electrical and mechanical faults in PMSM [21]. The main objective of this paper is to develop an experimental setup to teach methods of diagnosis of PMSM to students in Electrical Engineering Master's Degree. It is envisioned that using this experimental setup can be studied mechanical, electrical and magnetic failures. This requires a special design for synchronous permanent magnet machine.

\section{A. Permanent magnet machine prototype}

Next, the prototype design constraints necessary to cause the three types of faults are raised.

First, the authors decide on a frameless prototype. Therein the shaft is supported by two bearings whose position is adjustable as indicated in mark 1 of Fig. 2. This setting adjusts the shaft alignment causing defects of static eccentricity. Moreover the bearings can be easily replaced by other in poor condition to cause bearing failure.

It can also be adjusted the dynamic eccentricity due to movement of the pressure plate of the rotor sheets as seen in Fig. 3.

In order to easily lead to errors in the permanent magnets it has chosen to place them in the stator, in an interior permanent magnet synchronous machine configuration, as shown in mark 2 of Fig. 2. With this configuration, the permanent magnets do not need any fixing as its position is stable in its housing within the stator core. Thus they can be easily replaced with other previously demagnetized achieving the same effect as the fault occurs in the demagnetization. With the proposed configuration it can move or remove the permanent magnet with the machine running or even cause vibration in its housing. 


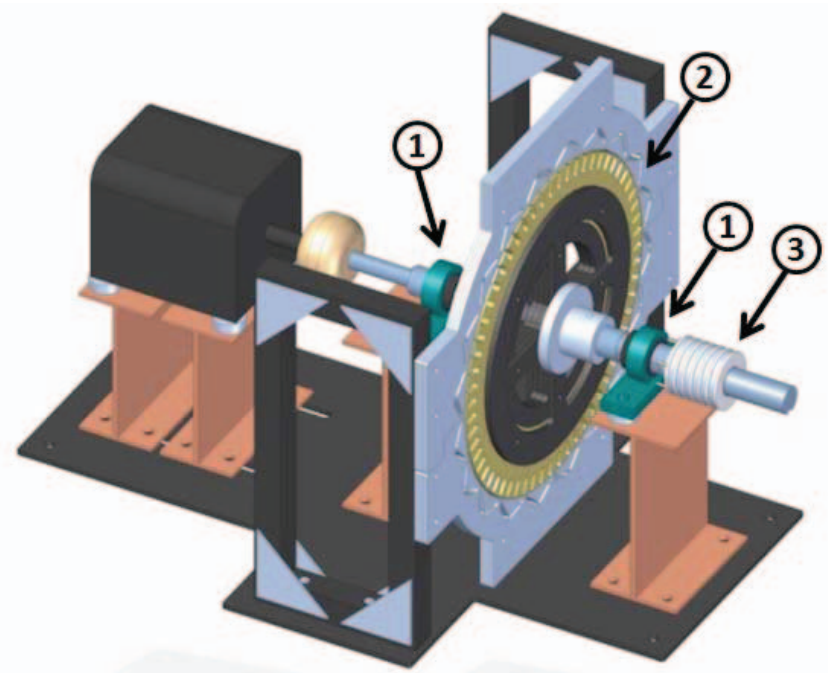

Fig. 2. Scheme of the prototype.



Fig. 3. Rotor assembly process.

This stator configuration without windings, allows it to be built in two halves (Fig. 4). Thus it can be dismantled without moving the rotor, which is held by external bearings.

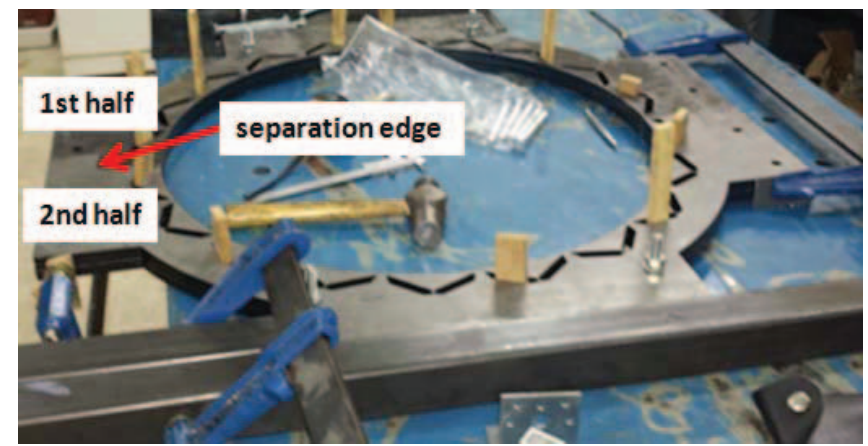

Fig. 4. Stator assembly process.

Finally in the rotor has been housed a three phase winding with all accessible coils, as shown in Fig. 5. Thus, it is possible to cause failures between turns and failures to the rotor core and it can be introduced different values in the fault resistance.

In order to feed the winding are arranged six slip-rings in the shaft which are accessed through brushes as shown in mark 3 of Fig. 2.

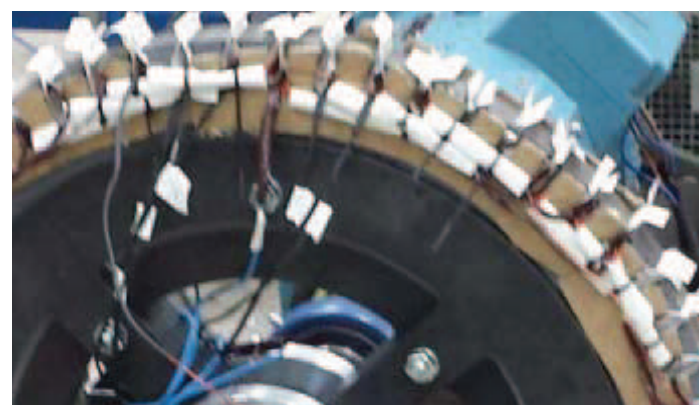

Fig. 5. Rotor winding details.

\section{B. Mechanical Drive}

The permanent magnet synchronous machine designed is mechanically coupled to a DC machine fed by a bidirectional converter. This mechanical drive was developed by the authors in a previous work to emulate a wind turbine [22]. However, with an adequate adaptation it can operate by providing a mechanical torque on the shaft when the faults on a permanent magnet generator are studied or providing a load torque when you want to study the faults on a permanent magnet motor.

The mechanical drive consists of a DC motor driven by a commercial microprocessor-based DC converter that is easily configurable. The converter is controlled by means of a PC and an input-output data acquisition device that has been programmed using the commercial software LABVIEW. The specific components used are:

1) A 7.5-kW DC machine.

2) An $\mathrm{AC} / \mathrm{DC}$ Siemens-Simoreg converter for $\mathrm{DC}$ drives. It supplies the suitable voltage/current to the DC machine in order to achieve the specified torque reference

3) An NI PCI-6014 Data Acquisition System. It calculates the torque reference depending of the motor or generation application.

\section{Electromagnetic DESIGN}

The input data for the design of the permanent magnet synchronous machine prototype are:

Output power: $\mathrm{P}=7 \mathrm{~kW}$.

Rotational speed: $\mathrm{n}=300 \mathrm{rpm}$

Permanent magnet characteristics: $\mathrm{B}_{\mathrm{r}}=1.2 \mathrm{~T}$; $\mathrm{H}_{\mathrm{c}}=880 \mathrm{kA} / \mathrm{m}$

With these specifications, using basic equations of permanent magnet machines sizing, the following parameters are determined (Table I): 
TABLE I

Basic Sizing Parameters of PeRmanent Magnet Machine PROTOTYPE

\begin{tabular}{l|l|l}
\hline Parameter & Symbol & Value \\
\hline Gap diameter & $\mathrm{D}$ & $588 \mathrm{~mm}$ \\
\hline Machine length & $\mathrm{L}$ & $20 \mathrm{~mm}$ \\
\hline Magnetic loading & $\mathrm{B}_{\mathrm{g}}$ & $0,57 \mathrm{~T}$ \\
\hline Electric loading & $\mathrm{A}$ & $34887 \mathrm{~A} / \mathrm{m}$ \\
\hline Pole pairs & $\mathrm{p}$ & 10 \\
\hline frequency & $\mathrm{f}$ & $50 \mathrm{~Hz}$ \\
\hline
\end{tabular}

In Table II the geometry of the magnetic circuit is as follows:

TABLE II

Magnetic CirCuit Details

\begin{tabular}{l|l|l}
\hline Parameter & Symbol & Value \\
\hline Air-gap thickness & $\mathrm{g}$ & $3 \mathrm{~mm}$ \\
\hline Slot number & $\mathrm{Q}$ & 60 \\
\hline Tooth width & $\mathrm{w}_{\mathrm{t}}$ & $20.4 \mathrm{~mm}$ \\
\hline PM number & $\mathrm{N}_{\mathrm{m}}$ & 40 \\
\hline PM thickness & $\mathrm{h}_{\mathrm{m}}$ & $10 \mathrm{~mm}$ \\
\hline PM width & $\mathrm{d}_{\mathrm{m}}$ & $40 \mathrm{~mm}$ \\
\hline
\end{tabular}

Finally, with all previous data the electrical specifications of the prototype can be calculated (Table III):

TABLE III

ELECTRIC RATING

\begin{tabular}{l|l|l}
\hline Parameter & Symbol & Value \\
\hline $\begin{array}{l}\text { Slot } \\
\text { number/pole/phase }\end{array}$ & $\mathrm{q}$ & 1 \\
\hline Layer number & 1 & 2 \\
\hline Turn number/phase & $\mathrm{N}$ & 210 \\
\hline Winding Factor & $\xi$ & 1 \\
\hline Voltage & $\mathrm{U}$ & $50 \mathrm{~V}$ \\
\hline Current & $\mathrm{I}$ & $51.85 \mathrm{~A}$ \\
\hline
\end{tabular}

Below are some results of tests conducted on the prototype are presented.

\section{EXPERIMENTAL RESULTS}

Fig. 6 shows an overview of the laboratory bench developed with the PMSM prototype and the DC drive:

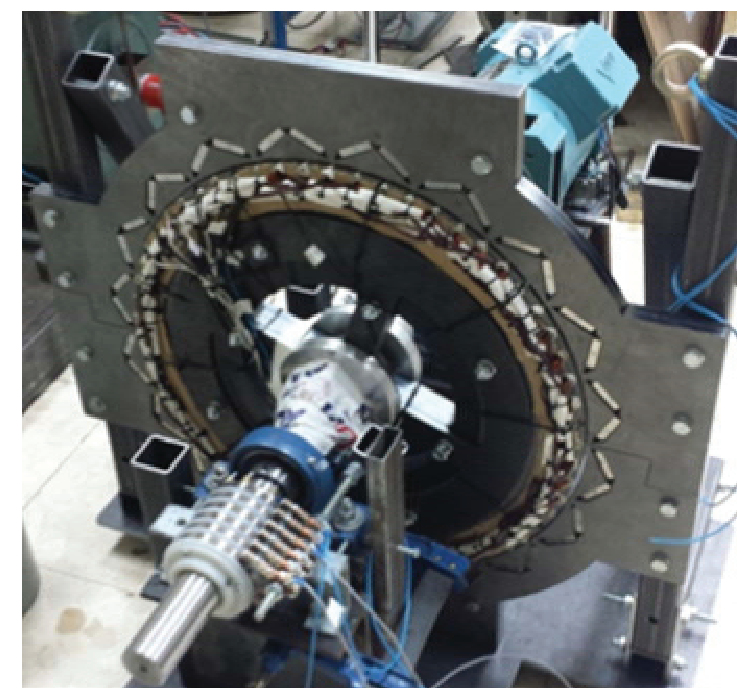

Fig. 6. Laboratory bench.

First Fig. 7 and Fig. 8 show, respectively, the induction map and the field lines map of the of the prototype, when it rotates without load at $300 \mathrm{rpm}$ driven by the DC machine.

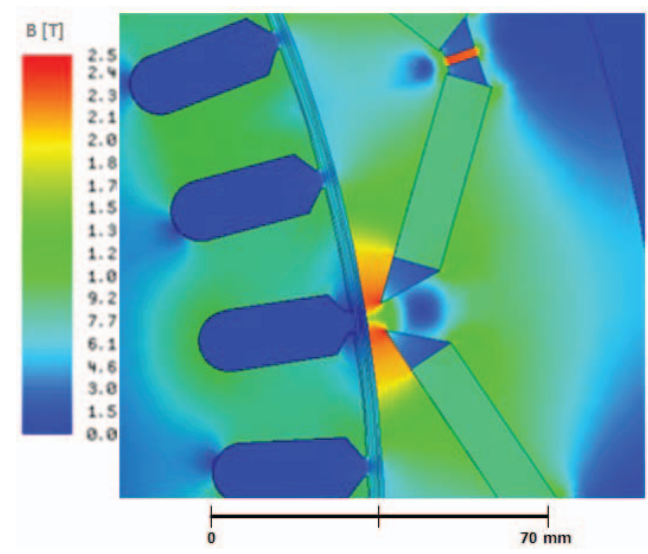

Fig. 7. Induction map in a machine pole.

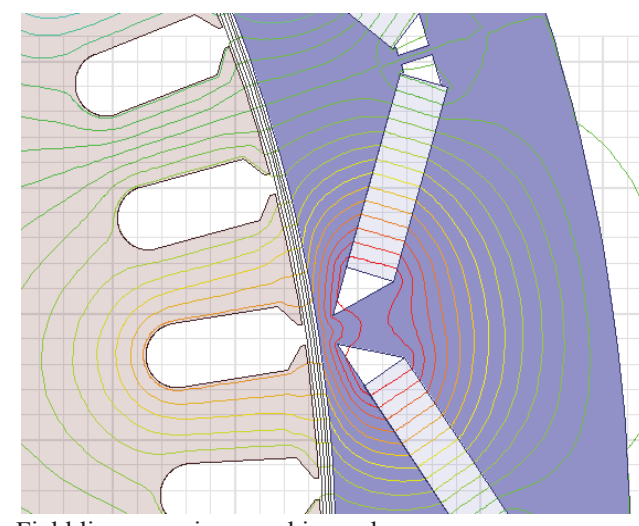

Fig. 8. Field lines map in a machine pole. 
For best viewing, the value of the induction in the air gap under a pole of the machine is shown in Fig. 9.

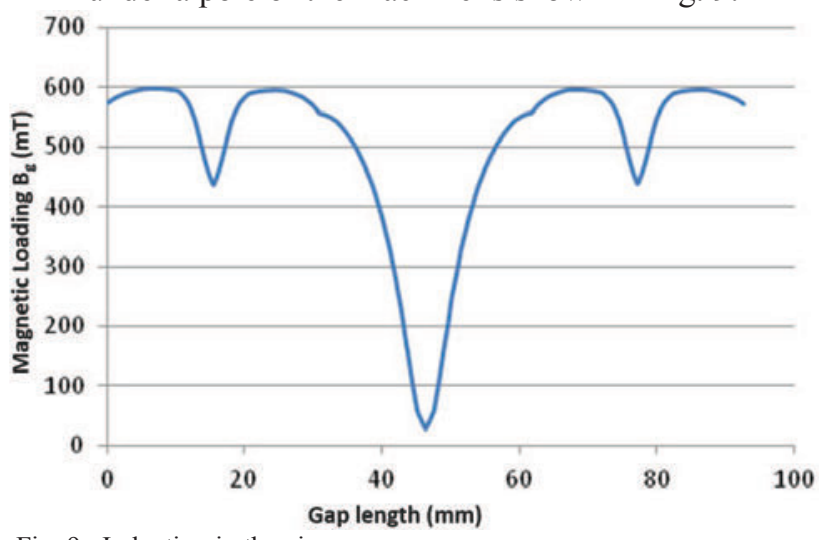

Fig. 9. Induction in the air gap.

As shown, the mean value is slightly smaller than expected, which explains that the no load voltage value is less than the design specifications, Fig. 10.

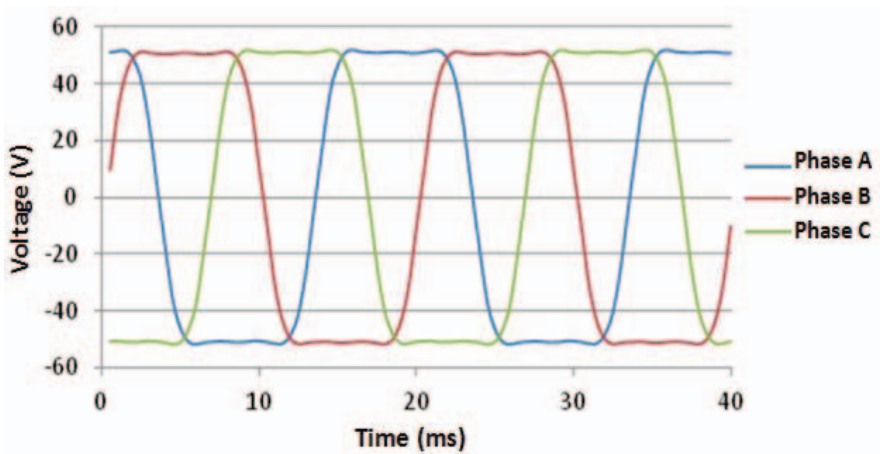

Fig. 10. Phase to neutral no load voltage.

Although the no load voltage is less, the tests show a constant ratio between the no load voltage value and the speed. Fig. 11 shows this issue:



Fig. 11. No load RMS voltage Vs rotational speed.

Some tests with different types of load were carried, by operating as a generator to obtain the expected behavior in this type of machine, as shown in Fig. 12.

Tests performed showed good agreement with previous simulations. For example, in Fig. 13 is presented the waveform with a $10 \Omega$ resistive load, both simulation and

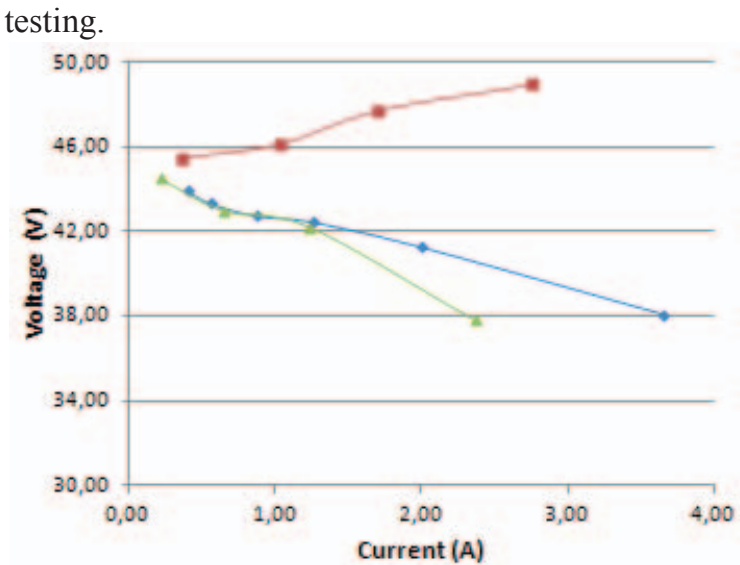

Fig. 12. External characteristic obtained through tests in capacitive load (red), resistive load (blue) and inductive load (green).
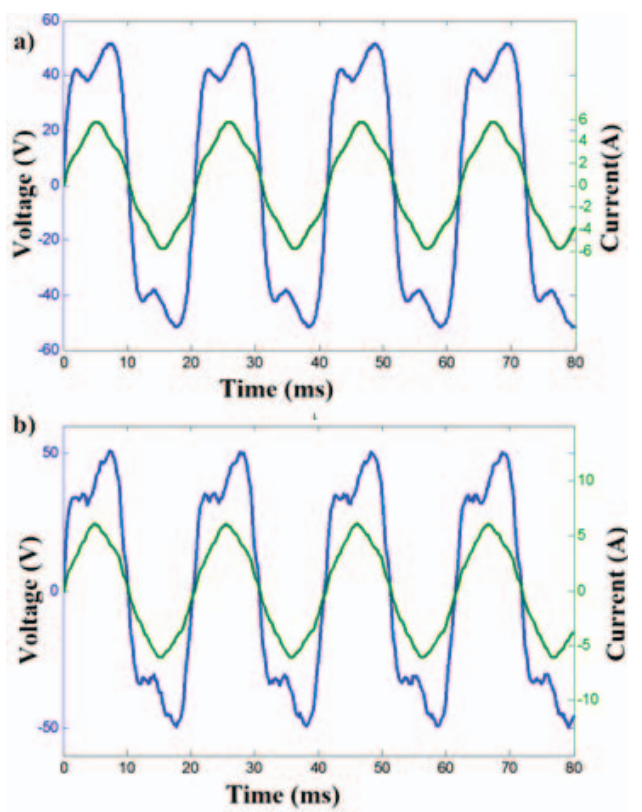

Fig. 13. PMSM with a $10 \Omega$ resistive load. a) Simulation results. b) Test result.

Finally, some tests have been performed subjecting the machine to demagnetization, eliminating some of the stator permanent magnets. In Fig. 14, one of the stator configuration is shown



Fig. 14. PMSM without three poles. 
In Fig. 15 is shown as the no load induced voltage is reduced as the stator permanent magnets are eliminated.

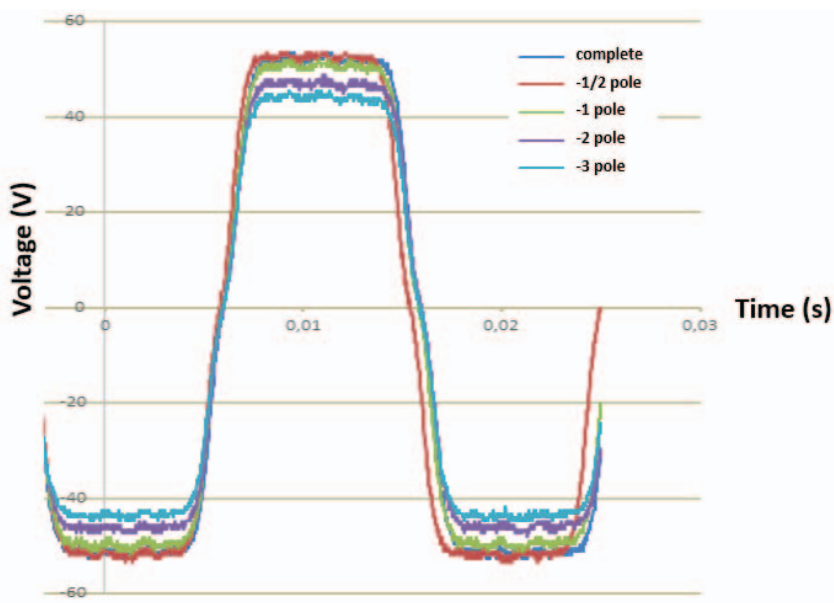

Fig. 15. No load inducted voltage with demagnetization

In Fig. 16, the voltage variation is shown as the load increases in the windings



\section{CONCLUSIONS}

In this paper after highlighting the increasing use in industry of PMSM, it has done a literature review of main faults that occur during its operation. Also it has reviewed the methods used to diagnose different faults.

The authors are professors in 'Monitoring and Diagnostics of Electrical Machines' in the Electrical Engineering Master's Degree from the Polytechnic University of Madrid and they have considered the need to teach and train their students in the diagnosis of PMSM. For this, they have begun to develop a laboratory bench with which to play all types of faults of the PMSM.

In this paper, authors have discussed in depth the design of the PMSM prototype as the most important element of the laboratory bench. They have made simulations and experimental results showing the correlation between the original specifications and the final behavior of the prototype designed.

\section{ACKNOWLEDGMENT}

The authors wish to acknowledge the technical support of Alstom Renovables SA, and especially J.A. Martínez, J. Villajos and F. Rodriguez-Camuñas.

\section{REFERENCES}

[1] E. Spooner and B. J. Chalmers, "An axial-flux permanent-magnet generator for a gearless wind energy system" IEEE Trans. Energy Conversion, vol. 14, no. 2, pp. 251, 257, Jun 1999.

[2] Wang, J.H.; Tan, F.W.; Jin, R.L., "Research on low-speed gearless permanent magnet synchronous motor for elevator drive," Electrical Machines and Systems, 2005. ICEMS 2005. Proceedings of the Eighth International Conference on , vol.1, no., pp.454,459 Vol. 1, 27-29 Sept. 2005.

[3] S. Belin, M. Scrooby, J.E. Masselus, T. Jobard, and S.Courtine, "A PMSM based control for traction applications," EPE Power Electronics and Motion Control Conference, 2003.

[4] M. Rosu, V. Nahkuri, A. Arkkio, T. Jokinen, J. Mantere, and J. Westerlund, "Permanent magnet synchronous motor for ship propulsion drive" International Conference on Electrical Machines, ICEM 1998.

[5] F. Sahin and A.J.A. Vandenpunt, "Design considerations of the flywheel-mounted axial-flux permanent-magnet machine for a hybrid electric vehicle," EPE Power Electronics and Motion Control Conference 1999

[6] S. Morimoto, Y. Takeda, and H. Murakami, "Motors for Home Applications -Development of Environment-Friendly Electric Motors -," EPE Power Electronics and Motion Control Conference 2002.

[7] Riba Ruiz, J.-R.; Rosero, J.A.; Espinosa, A.G.; Romeral, L., "Detection of Demagnetization Faults in Permanent-Magnet Synchronous Motors Under Nonstationary Conditions," Magnetics, IEEE Transactions on, vol.45, no.7, pp.2961,2969, July 2009.

[8] Bianchi, N ; Pré, M.D.; Bolognani, S., "Design of a fault-tolerant IPM motor for electric power steering," Vehicular Technology, IEEE Transactions on, vol.55, no.4, pp.1102,1111, July 2006.

[9] Aston A.; "China's Rare-Earth Monopoly", Technology review, October 15, 2010.

[10] EL-Refaie A., Johnson F.: "Alternative High-Performance Motors with Non-Rare Earth Materials", GE Global Research May 16, 2012

[11] Bellini, A.; Filippetti, F.; Tassoni, C.; Capolino, G.-A., "Advances in Diagnostic Techniques for Induction Machines," Industrial Electronics, IEEE Transactions on, vol.55, no.12, pp.4109,4126, Dec. 2008.

[12] Nandi, S.; Toliyat, H.A., "Novel frequency-domain-based technique to detect stator interturn faults in induction machines using statorinduced voltages after switch-off," Industry Applications, IEEE Transactions on, vol.38, no.1, pp.101,109, Jan/Feb 2002.

[13] Ebrahimi, B.M.; Faiz, J., "Feature Extraction for Short-Circuit Fault Detection in Permanent-Magnet Synchronous Motors Using StatorCurrent Monitoring," Power Electronics, IEEE Transactions on, vol.25, no.10, pp.2673,2682, Oct. 2010.

[14] Filippetti, F.; Franceschini, G.; Tassoni, C; Vas, P., "Recent developments of induction motor drives fault diagnosis using AI techniques," Industrial Electronics, IEEE Transactions on, vol.47, no.5, pp.994,1004, Oct 2000.

[15] De Araujo Ribeiro, R.L.; Jacobina, C.B.; da Silva, E.R.C.; Lima, A.M.N., "Fault-tolerant voltage-fed PWM inverter AC motor drive systems," Industrial Electronics, IEEE Transactions on, vol.51, no.2, pp.439,446, April 2004.

[16] Estima, J.O.; Marques Cardoso, A.J., "A New Approach for RealTime Multiple Open-Circuit Fault Diagnosis in Voltage-Source Inverters," Industry Applications, IEEE Transactions on, vol.47, no.6, pp.2487,2494, Nov.-Dec. 2011 
[17] Kim, U.; Lieu, D.K., "Magnetic field calculation in permanent magnet motors with rotor eccentricity: with slotting effect considered," Magnetics, IEEE Transactions on , vol.34, no.4, pp.2253,2266, Jul 1998.

[18] Le Roux, W.; Harley, R.G.; Habetler, T.G., "Detecting Rotor Faults in Low Power Permanent Magnet Synchronous Machines," Power Electronics, IEEE Transactions on, vol.22, no 1, pp 322,328, Jan. 2007.

[19] Rosu, M ; Saitz, J.; Arkkio, A., "Hysteresis model for finite-element analysis of permanent-magnet demagnetization in a large synchronous motor under a fault condition," Magnetics, IEEE Transactions on, vol.41, no.6, pp.2118,2123, June 2005.

[20] Ebrahimi, B.M.; Faiz, J.; Roshtkhari, M.J., "Static-, Dynamic-, and Mixed-Eccentricity Fault Diagnoses in Permanent-Magnet Synchronous Motors," Industrial Electronics, IEEE Transactions on, vol.56, no.11, pp.4727,4739, Nov. 2009.

[21] Strangas, E.G.; Aviyente, S.; Zaidi, S.S.H., "Time-Frequency Analysis for Efficient Fault Diagnosis and Failure Prognosis for Interior PermanentMagnet AC Motors," Industrial Electronics, IEEE Transactions on, vol.55, no.12, pp.4191,4199, Dec. 2008.

[22] Arribas, J.R.; Veganzones, C.; Blazquez, F.; Platero, C.A.; Ramirez, D.; Martinez, S.; Sanchez, J.A.; Herrero Martinez, N., "Computer- Based Simulation and Scaled Laboratory Bench System for the

Teaching and Training of Engineers on the Control of Doubly Fed

Induction Wind Generators," Power Systems, IEEE Transactions on, vol.26, no.3, pp.1534,1543, Aug. 2011. 